Research Article

\title{
Behavior of Axially Loaded Stirrup Confinement Rectangular Concrete-Filled Steel Tubular Stub Columns
}

\author{
Jing Liu $\mathbb{D}^{1,2}$ Wen-jun Wang $\mathbb{D}^{1,}{ }^{1}$ Fa-xing Ding $\left(\mathbb{D},{ }^{1}\right.$ Xin-fa Zeng, ${ }^{2}$ Zhe Tan, ${ }^{2}$ Yan Huang, \\ and Bao-quan Wang 2 \\ ${ }^{1}$ School of Civil Engineering, Central South University, Changsha, Hunan Province 410075, China \\ ${ }^{2}$ School of Civil Engineering, Hunan City University, Yiyang, Hunan Province 413000, China \\ Correspondence should be addressed to Wen-jun Wang; wenjunwang@csu.edu.cn and Fa-xing Ding; dinfaxin@csu.edu.cn
}

Received 15 June 2019; Accepted 2 November 2019; Published 2 December 2019

Academic Editor: Daniele Baraldi

Copyright (C) 2019 Jing Liu et al. This is an open access article distributed under the Creative Commons Attribution License, which permits unrestricted use, distribution, and reproduction in any medium, provided the original work is properly cited.

\begin{abstract}
This article presents the experimental and finite element (FE) analyses of two conventional rectangular concrete-filled steel tubular (CFT) stub columns, two stiffened rectangular concrete-filled steel tubular (SCFT) stub columns, and two stirrup confinement rectangular concrete-filled steel tubular (CCFT) stub columns concentrically loaded in compression to failure. The influences of the ductility and ultimate bearing strength of these stub columns with stiffening ribs or spiral stirrup confinement were discussed. Abaqus was used to establish a 3D FE model and analyze the properties of CFT stub columns subjected to axial compression. The effect of the concrete core and rectangular steel tube under loop stirrup confinement was discussed. Analytical results showed that spiral stirrup confinement can availably retard the local bucking of the rectangular steel pipe, and the effect of the spiral stirrup confinement was stronger than that of stiffeners. The DI values of SCFT and CCFT were $21.9 \%$ and $31.9 \%$ larger than those of CFT, respectively. The ultimate capacity values of SCFT and CCFT were $10.2 \%$ and $18 \%$ larger than those of CFT, respectively. The ductility and ultimate bearing strength of the specimens improved effectively under spiral stirrup confinement, and the ductility of the CCFT columns was preferable to that of the SCFT columns.
\end{abstract}

\section{Introduction}

The development of modern materials, design theories, and construction techniques has facilitated the growth of steel structures with high building heights, long spans, and heavy loads, which increase the required bearing capacity of columns. Rectangular and square concrete-filled steel tubular (CFT) columns are widely used in engineering because of their easy column-to-beam connections, high flexural stiffness, and flexible building layouts, but the steel tubes exert a poor restraint effect on concrete before reaching their ultimate bearing capacity, and the ductility and ultimate flexural capacity of these columns need improvement [1-3].

Several studies have illustrated that steel-reinforced concrete columns cannot provide effective restraint on core concrete, and the complex construction procedures involve profiled steel, longitudinal reinforcement, stirrup, and concrete. Circular CFT columns can provide sufficient restraint to core concrete from steel pipes. The bending capacity and flexural rigidity of circular CFT columns are relatively low, but the joint structure connecting the beams and the columns is particularly sophisticated.

In recent years, many scholars have studied the arrangement of rectangular CFT stub columns with stiffening ribs [4-7] and binding bars [8-11] to enhance their ductility and bearing strength. Test results show that the abovementioned treatment methods of rectangular CFT stub columns can improve the constraint of steel pipes to core concrete, effectively limit transverse deformation, and weaken the appearance of the local expansion of steel pipes.

Chen et al. [12] and Sun et al. [13] discussed the compressive behavior of reinforced concrete columns confined by multispiral hoops, which showed the strength and ductility of the column can be greatly enhanced due to better confinement. Inspired by this approach, we design a new type of column, namely, stirrup confinement rectangular 
CFT stub column (CCFT), to overcome the shortage of conventional CFT stub columns and steel-reinforced concrete columns. On the basis of the conventional rectangular CFT columns, the stirrup is used to strengthen the restraint of concrete. In comparison with steel-reinforced concrete columns, such as square, circular, and rectangular CFT stub columns, CCFT features the following advantages.

(1) CCFT stub columns have a lower steel content than steel-reinforced concrete columns, thereby overcoming various problems, such as complicated application technology, difficult concrete vibration and pounding, and large amounts of formwork caused by multiple construction procedures and complicated joint construction. (2) Unlike in the conventional rectangular CFT stub columns, the rectangular steel tube mainly acts as a restriction on the concrete in the corner, and the inward-cut elliptic stirrups or spiral stirrups act as a restriction on the core concrete, and the local buckling of the side wall of the steel tube was restrained. Therefore, the ductility and bearing strength of the rectangular CFT stub columns are considerably improved while retaining the convenience of joint construction. Meanwhile, it is beneficial to reduce the size of the structure and increase the effective usable area of the building for the same load condition and material amount.

This study analyzed two conventional rectangular CFT, two ribbed rectangular CFT, and two stirrup confinement rectangular CFT axial compression stub columns. The mechanical properties of the axial compression specimens were explored under different constraint conditions. A 3D finite element (FE) model was developed for numerical analysis by using Abaqus, and the composite action among the concrete, stirrups, and steel pipe was revealed.

\section{Experimental Study}

2.1. Testing Conditions. Six CFT stub columns were included in this article. The nominal dimension of the rectangle CFT stub columns was $(B) 250 \mathrm{~mm} \times(D) 150 \mathrm{~mm} \times(t) 4 \mathrm{~mm} \times(L)$ $750 \mathrm{~mm}$, where $B$ and $D$ are the long and short sides of the rectangle section, respectively, $t$ is the steel tube wall thickness, and $L$ is the height of the CFT stub columns and stiffening ribs. $f_{\mathrm{s}}$ is the yield strength of the stiffening rib and steel pipe, $f_{\mathrm{t}}$ is the yield strength of the stirrup, and $f_{\mathrm{cu}}$ is the cubic compressive strength of concrete. $t_{2}$ and $w$ are the thickness and width of the stiffening ribs, respectively. $d$ is the longitudinal spacing of the stirrups, and $N_{\mathrm{u}}$ means the limited capacity of the specimens. Table 1 shows details of the specimens.

For the six specimens, welding technology was applied on the basis of the standard for the design of steel structures (GB 50017-2017) [14]. The stiffening rib in the RST2 specimen was composed of the same type of steel as the steel tube. The elliptical stirrups in RST3 comprised plain round bars with a diameter of $6 \mathrm{~mm}$. Four longitudinal bars with equal diameters and lengths were used to weld the elliptical stirrup, and the reinforcement cage was placed into the rectangular steel pipe. The elliptical spiral bars were spotwelded with equal intervals of the inner wall of the rectangular steel pipe. The cross sections of the specimens are shown in Figure 1.
For failure model observation and specimen deformation, the hollow rectangular steel tube specimens should be evenly coated with red paint, and a $50 \mathrm{~mm} \times 50 \mathrm{~mm}$ grid was drawn on the steel tube surface. A rectangular plate was applied to cover the steel pipe, and concrete was poured onto the specimen and vibrated until it was compacted. The standard concrete cubes were cured in the same atmospheric environment as those for the CFT specimens to measure the concrete strength of the structured entities. Table 2 shows the composition of the used C40grade commercial concrete.

2.2. Test Program. The steel and concrete properties were tested. The measured yield strengths of the rebar and steel tube were 363.5 and $327.7 \mathrm{MPa}$, respectively, and the concrete compressive strength was $40.4 \mathrm{MPa}$. The short column specimen was tested on a 500-ton triaxial stress tester.

For accurate specimen deformation, several strain gauges were arranged on the section of each specimen relative to the steel plate, and two electrical displacement meters were arranged on the other side. Figure 2 shows the test specimens and instrumentation, and Figure 3 presents the experimental setup. Strain and deformation data were collected using a static strain measurement system and electronic displacement meter, respectively.

The test loading system was as follows: in the elastic stage, $1 / 10$ of the bearing capacity load was increased per load. In the elastic-plastic stage, 1/20 of the ultimate load was increased per load. The CFT stub columns were constantly loaded until failure. The failure process and mode were observed, and the displacement, ultimate load, and strain of the steels were recorded. Each specimen test lasted approximately $2 \mathrm{~h}$.

2.3. Test Phenomenon. The damage process of the specimens can be classified into the following three stages:

(1) Elastic Stage. The load-train curve of the CFT columns was generally linear before $60 \%-80 \%$ of the peak loading. No distinctive local buckling was observed outside the steel pipe. The hoop tensile strain of the steel pipe was small before the load reached $30 \%$ of the peak load.

(2) Elastic-Plastic Stage. Tensile cracks appeared in the concrete with increasing load. When the applied load achieved $60 \%-80 \%$ of the ultimate load, the loaddisplacement curves illustrated elastic-plastic behavior, the compression stiffness of the specimens continuously declined, and the load-vertical/hoop strain curve showed a noticeable nonlinear behavior.

(3) Failure Stage. When the imposed load continuously increased until the peak load was reached, steel tube deformation developed rapidly, the core concrete was crushed rapidly, and the carrying capacity of the CFT columns decreased rapidly. Figure 4 shows the failure modes of all CFT columns.

2.4. Local Buckling Analysis. For the conventional CFT axial compression short column (RST1), when the load reached 
TABLE 1: Characteristics and geometric properties of CFT specimens.

\begin{tabular}{|c|c|c|c|c|c|c|c|c|c|c|}
\hline No. & $B \times D \times t(\mathrm{~mm})$ & $L(\mathrm{~mm})$ & $f_{\mathrm{cu}}(\mathrm{MPa})$ & $f_{\mathrm{s}}(\mathrm{MPa})$ & $f_{\mathrm{r}}(\mathrm{MPa})$ & $W \times t_{2}(\mathrm{~mm})$ & $D(\mathrm{~mm})$ & $N_{\mathrm{u}}(\mathrm{kN})$ & $\xi$ & $D I$ \\
\hline RST1-A & $248.5 \times 151.4 \times 3.70$ & \multirow{6}{*}{750} & \multirow{6}{*}{40.4} & \multirow{6}{*}{327.7} & - & - & - & 1980 & 0.083 & 1.705 \\
\hline RST1-B & $249.0 \times 151.0 \times 3.75$ & & & & - & - & - & 1851 & 0.085 & 1.515 \\
\hline RST2-A & $248.5 \times 151.1 \times 3.65$ & & & & - & $30.38 \times 3.72$ & - & 2075 & 0.090 & 1.882 \\
\hline RST2-B & $248.3 \times 151.3 \times 3.69$ & & & & - & $31.20 \times 3.75$ & - & 2145 & 0.091 & 2.043 \\
\hline RST3-A & $249.8 \times 150.3 \times 3.63$ & & & & \multirow{2}{*}{363.5} & - & 50 & 2280 & 0.094 & 1.928 \\
\hline RST3-B & $249.0 \times 151.3 \times 3.62$ & & & & & 一 & 50 & 2237 & 0.093 & 2.319 \\
\hline
\end{tabular}

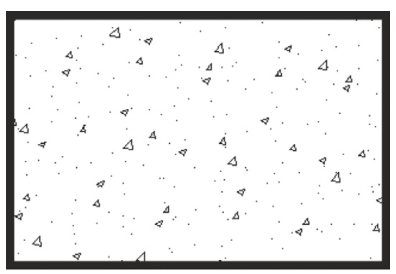

(a)

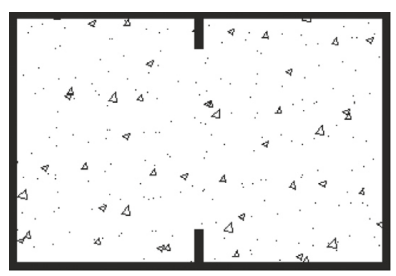

(b)

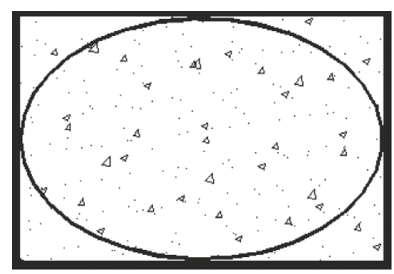

(c)

FIGURE 1: Cross sections of specimens. (a) Specimens without confinement (RST1), (b) specimens with stiffening rib (RST2), and (c) specimens with stirrups (RST3).

TABLE 2: Concrete proportioning design.

\begin{tabular}{lcccc}
\hline Concrete grade & Cement $\left(\mathrm{kg} / \mathrm{m}^{3}\right)$ & Sand $\left(\mathrm{kg} / \mathrm{m}^{3}\right)$ & Water $\left(\mathrm{kg} / \mathrm{m}^{3}\right)$ & Aggregate $\left(\mathrm{kg} / \mathrm{m}^{3}\right)$ \\
\hline C40 & 420 & 320 & 168 & 1201 \\
\hline
\end{tabular}



(a)

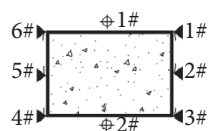

Cross section of rectangular CFT

(b)

Figure 2: Test specimen and instrumentation.

approximately $60 \%$ of the peak capacity, local distortion appeared at different locations of the CFT columns with increasing load, and the end and central parts became the fastest-growing of all regions.

For the SCFT with internal stiffening ribs (RST2), local buckling appeared until the load approached about $80 \%$ of the peak capacity, which was distinctly delayed relative to that of the conventional rectangular CFT columns.

For the CCFT stub columns (RST3), local deformation of the confinement occurred only when the columns approached their ultimate bearing capacity. The local distortion of steel pipes can be effectively alleviated when

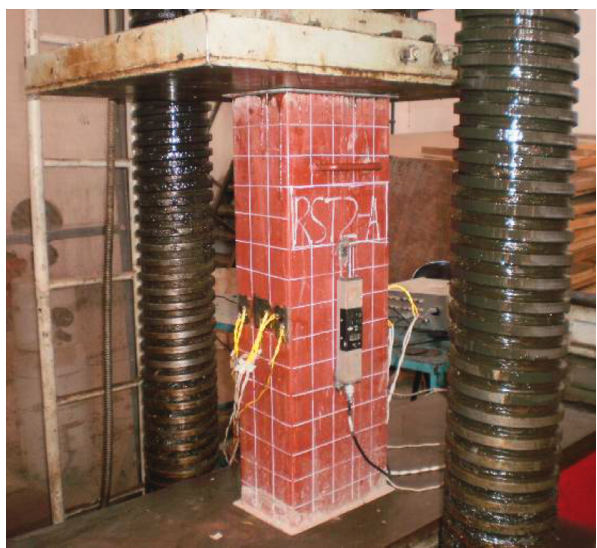

FIgURE 3: Experimental setup. setting the internal constraint of the elliptical stirrup. The confined effect of RST3 was more effective than that of RST2.

2.5. Capacity Analysis. Figure 5 shows the comparison of specimen capacity. The following results were obtained:

(1) Unlike the ultimate carrying capacity of the specimens without internal restraints (RST1) that of the RST2 specimens improved after stiffeners were set on the long side because of the constraint by the stiffeners on the core concrete. Compared with the steel ratio and bearing capacity of the specimens without internal 


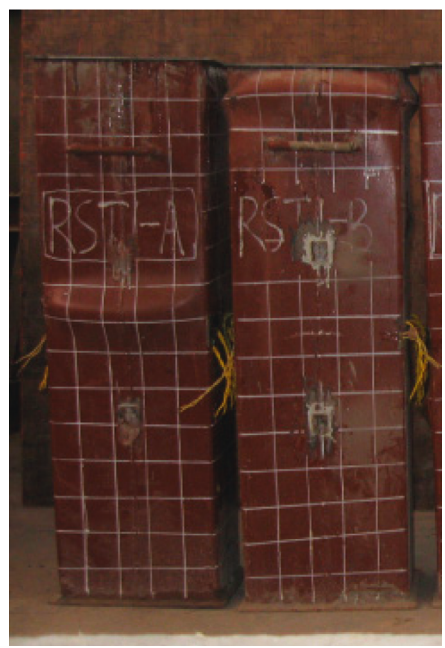

(a)

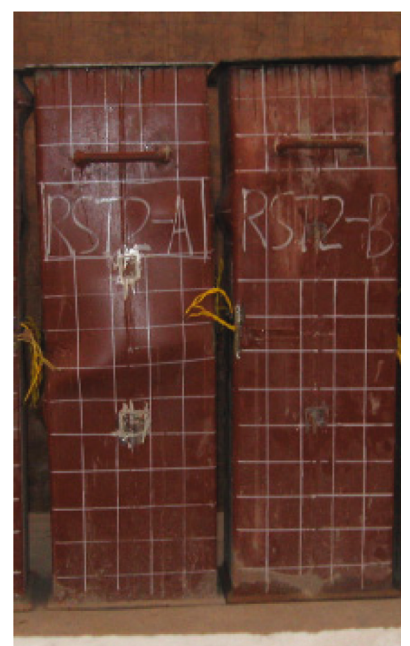

(b)

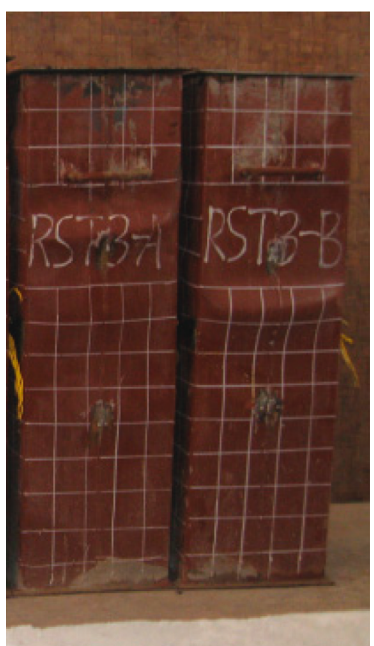

(c)

Figure 4: Failure modes. (a) RST1. (b) RST2. (c) RST3.

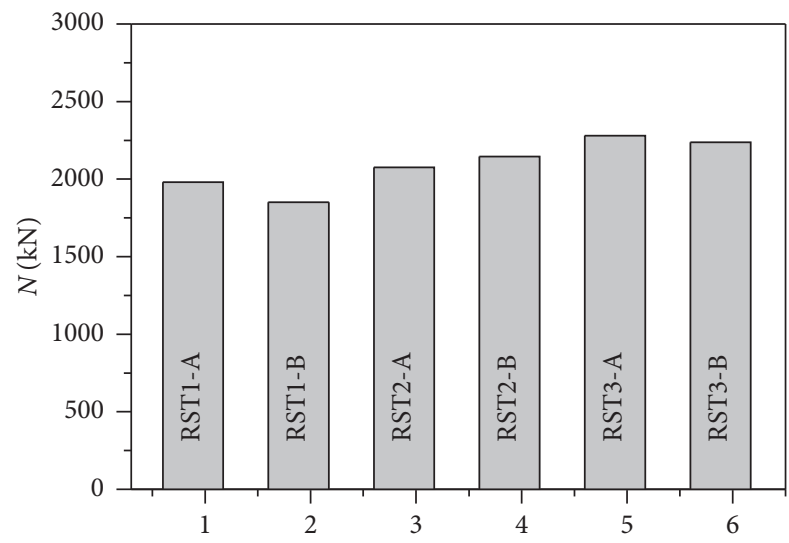

Figure 5: Comparison of specimen capacity.

restraints (RST1 series), those of RST2 increased by $7.7 \%$ and $10.2 \%$, respectively, on average.

(2) When the internal shear elliptical stirrup (RST3) was set, the ultimate carrying capacity of the specimens significantly increased because of the dual constraints of the external steel tube and internal elliptical stirrup on the core concrete, and the ultimate bearing strength decreased slowly in the failure stage. Compared with the steel ratio of conventional CFT (RST1) that of RST3 increased by $11.3 \%$, and the bearing capacity increased by $18 \%$ on average.

2.6. Ductility Analysis. For quantification of the influence of different internal constraint forms on the ductility of the specimens, the ductility index of the CFT stub columns was expressed as

$$
D I=\frac{\varepsilon_{0.85}}{\varepsilon_{\mathrm{u}}},
$$

where $\varepsilon_{\mathrm{u}}$ is the axial strain at the peak load of the CFT stub columns and $\varepsilon_{85 \%}$ is the axial strain when the load decreases to $85 \%$ of its peak load.
On the basis of the definition of $D I$, a slow load drop would result in a large DI and good ductility of the specimen. Table 1 shows the ductility index of this test. Figure 6 presents the influence of different forms of internal constraints on the ductility $D I$ of the specimen section. The constraint forms effectively improved the ductility of the specimens. The DI values of RST2 and RST3 were $21.9 \%$ and $31.9 \%$ larger than those of RST1, respectively.

\section{FE Analysis}

3.1. FE Modeling. In the present work, FE models were built using the Abaqus/Standard 6.8 program [15]. Table 3 shows the element type of the CFT component. Ding et al. [16] and Liu et al. [17] provided detailed modeling parameters and constitutive material models. Figure 7 presents the FE model of the CFT columns.

Tie was used to model the constraint between the loading plate and concrete and that between the end plate and concrete. Thus, relative motion did not occur when these materials were separated. The constraint between the end plate and steel tube was shell-to-solid coupling. In the FE analysis modeling, the loading plate was subjected to axial compression through a displacement control method, and the end plate was fixed.

3.2. Results and Analysis. Figure 8 compares the load-longitudinal strain curves of the CFT stub columns that were obtained through FE analysis with test. The proposed FE model can imitate the load-longitudinal strain curves of the CFT stub columns with high precision. In the elastic stage, the increasing parts of the simulated load-longitudinal strain curves nearly matched the test curves. In the elastic-plastic and failure stages, the FE curves deviated from the test curves to some extent.

Figure 9 presents the comparison of the load-longitudinal and load-transverse strain curves between the numerical and experimental studies on the CFT stub columns. 


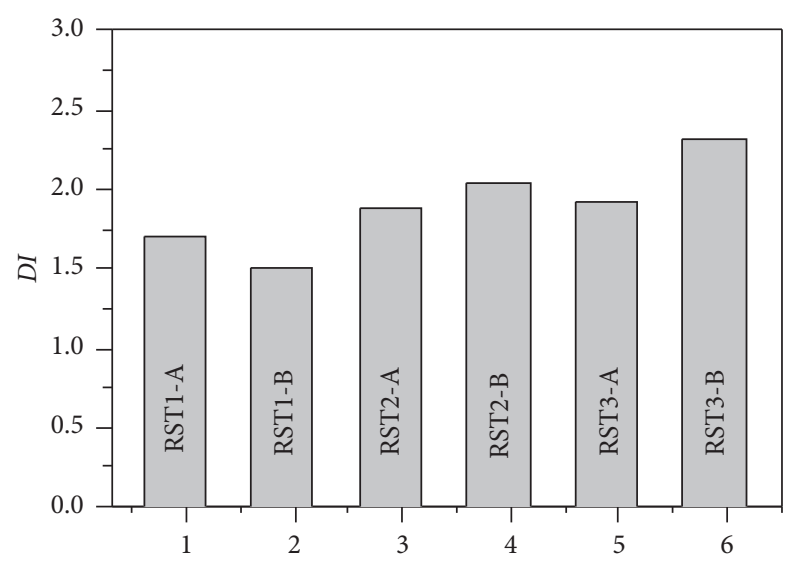

Figure 6: Comparison of the $D I$ value.

TABLE 3: Element type of the CFT component.

\begin{tabular}{lcc}
\hline No. & Component & Element type \\
\hline 1 & Steel tube, stiffing rib & Four-node reduced integral format shell element S4R \\
2 & Concrete, loading plate & Eight-node brick element C3D8R \\
3 & Rebar & Two-node linear beam element B31 \\
\hline
\end{tabular}

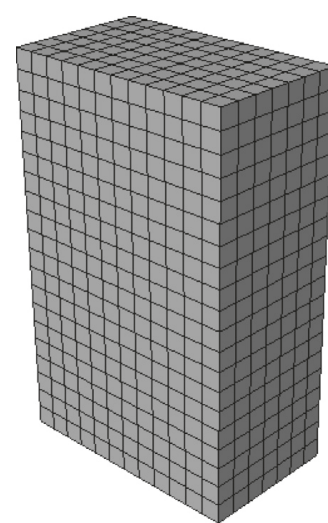

(a)

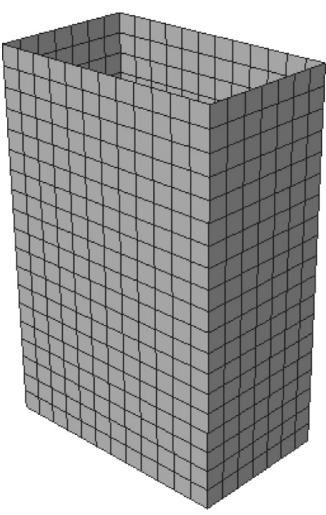

(b)

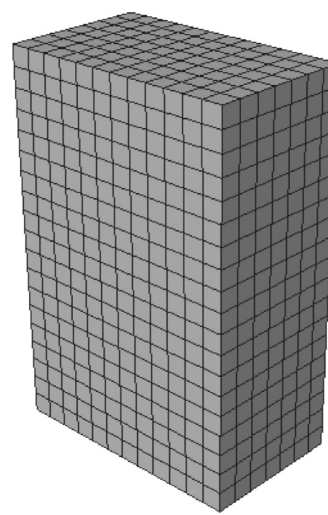

(c)

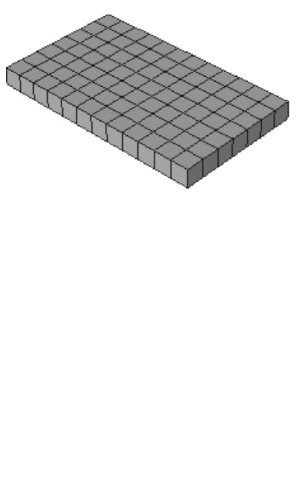

(d)

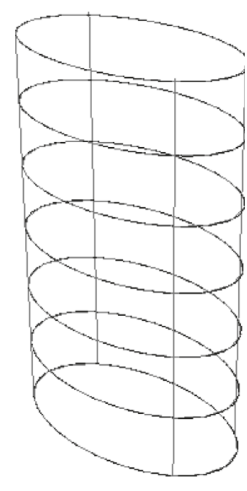

(e)

Figure 7: FE model of the CFT columns. (a) 1/2 total model, (b) steel pipe, (c) concrete, (d) loading plate, and (e) stirrup.
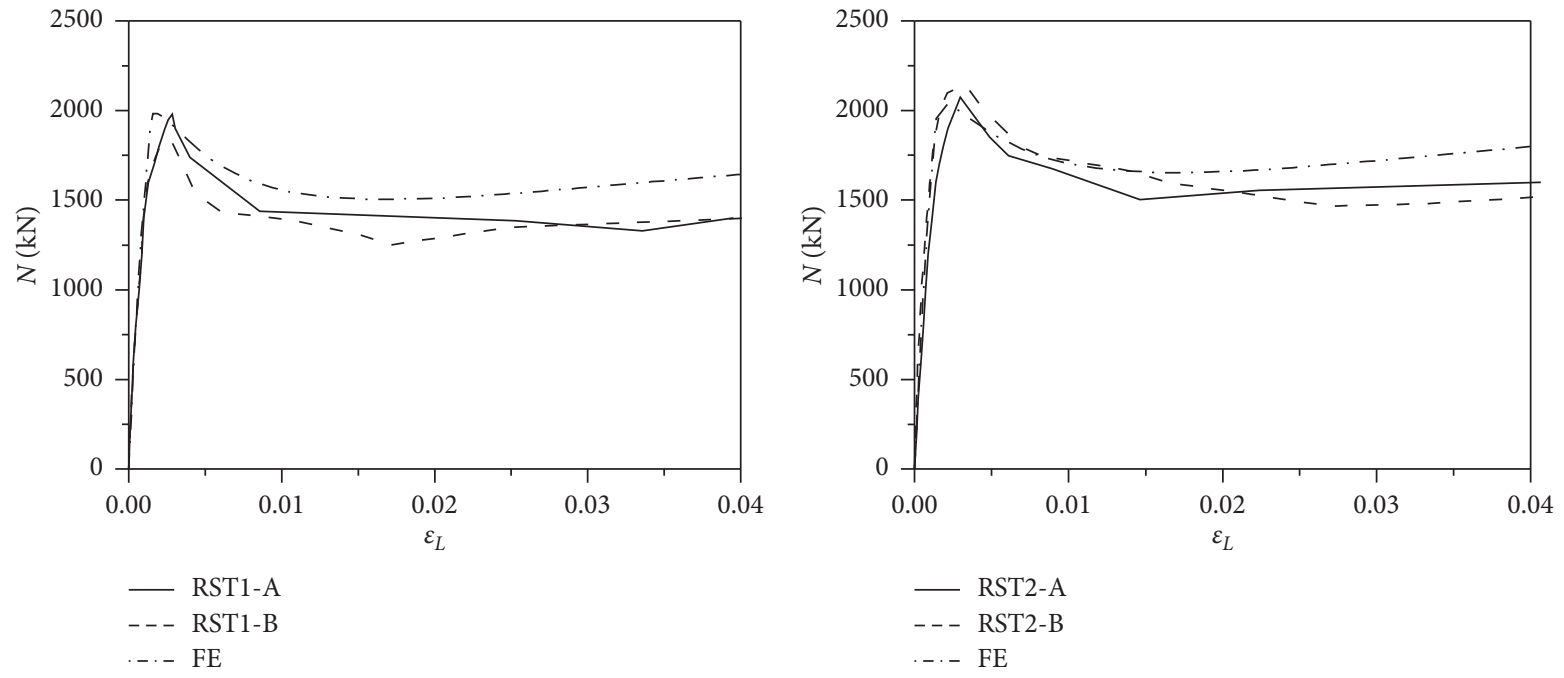

(a)

(b)

Figure 8: Continued. 


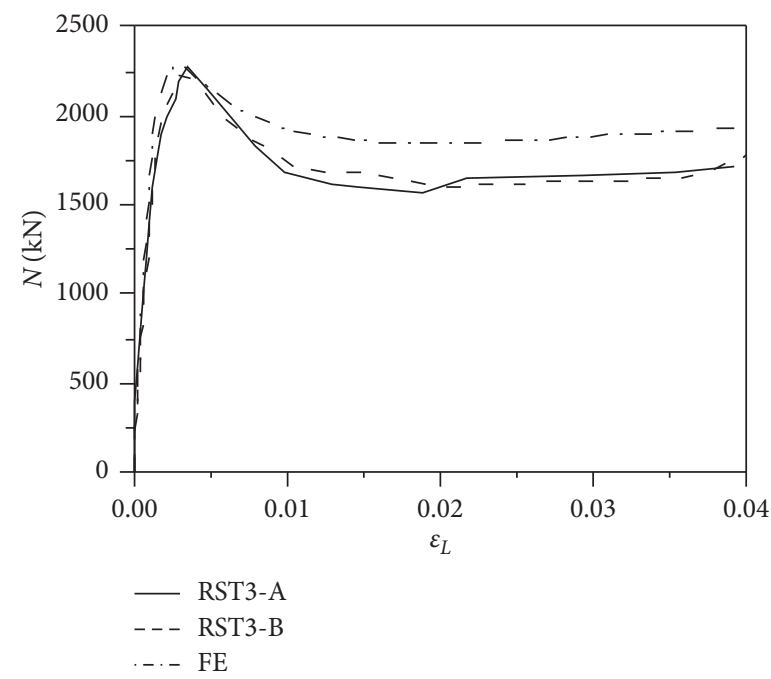

(c)

FIgURE 8: Comparison of $N-\Delta$ curves obtained from numerical and experimental studies. (a) RST1, (b) RST2, and (c) RST3.

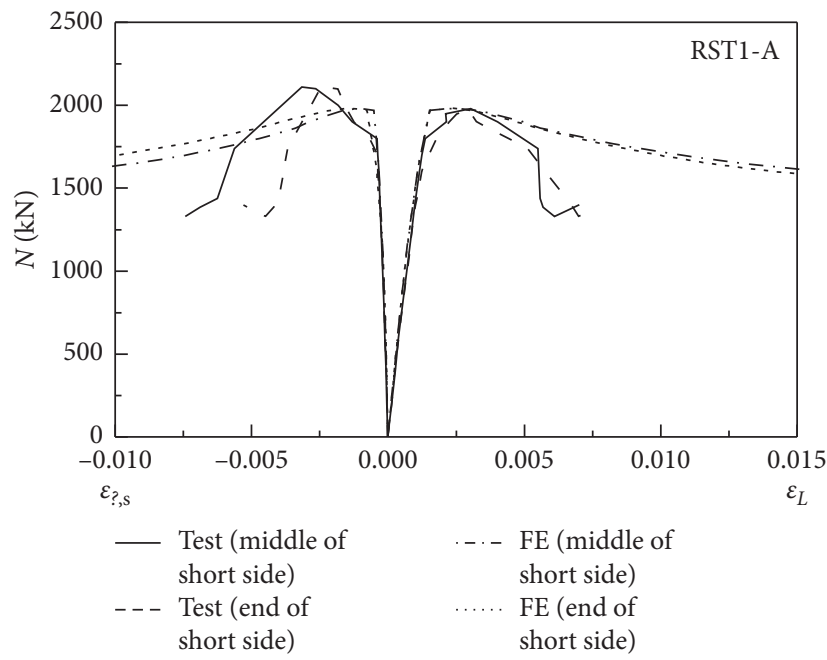

Figure 9: Comparison of $N-\varepsilon$ curves obtained from numerical and experimental studies.

The load-longitudinal/transverse strain curves linearly changed in the elastic stage. The data obtained from the FE analysis and test results coincided well. The deflection showed a nonlinear growth as the load reached the yield load, local buckling was observed in the specimen, and deformation increased rapidly. The strain curve obtained by the FE results fits poorly with the test data.

On the basis of the verification of experimental results, the typical rectangular specimens were analyzed, the loaddeformation curves of the rectangular CFT specimens with the same steel content were investigated, and the restraint effects of the rectangular steel pipe, stirrup, and concrete under load were discussed.

The rectangular axial compression CFT (RST-A), which has internal restraint ring stirrups, was selected. The parameters were as follows: specimen length $L=900 \mathrm{~mm}$, long side $B=300 \mathrm{~mm}$, short side $D=200 \mathrm{~mm}$, stirrup spacing $S=50 \mathrm{~mm}$, concrete strength $f_{\mathrm{cu}}=60 \mathrm{MPa}$, steel tube yield strength $f_{\mathrm{s}}=345 \mathrm{MPa}$, steel tube thickness $t=6 \mathrm{~mm}$, elliptical stirrup diameter $d=8 \mathrm{~mm}$, and stirrup yield strength $f_{\mathrm{t}}=335 \mathrm{MPa}$. The steel tube thickness of the ordinary rectangular CFT (RST-B) had the same sectional area and steel rate, that is, $t=6.89 \mathrm{~mm}$, and the other parameters were the same as those of RST-A.

Figure 10 shows the comparison of the stirrup, concrete, and steel tube stress between the experimental and FE analysis results. The following conclusions are drawn:

(1) The transverse tensile and axial compressive stress curves of the steel pipe at the endpoints of the rectangular CFT (RST-A) intersected in the loading procedure, and the sequence at the midpoint was earlier than that at the endpoint. Thus, the restraining action of the rectangular steel pipe on the core concrete was better at the endpoint than at the midpoint. 


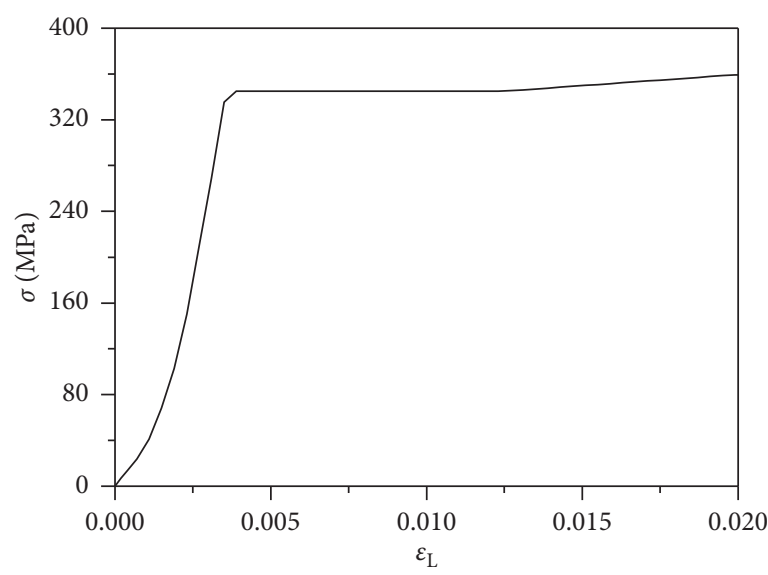

RST-A stirrup

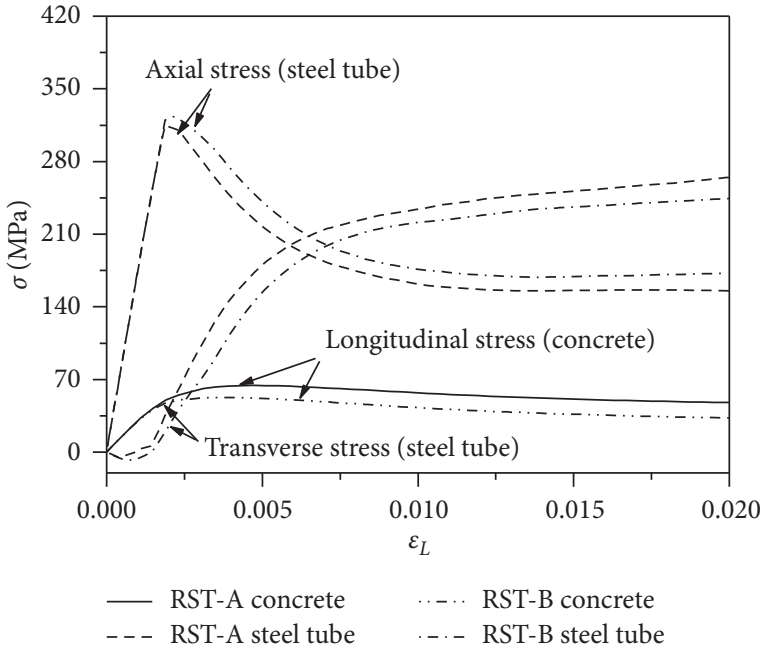

(b)

(a)

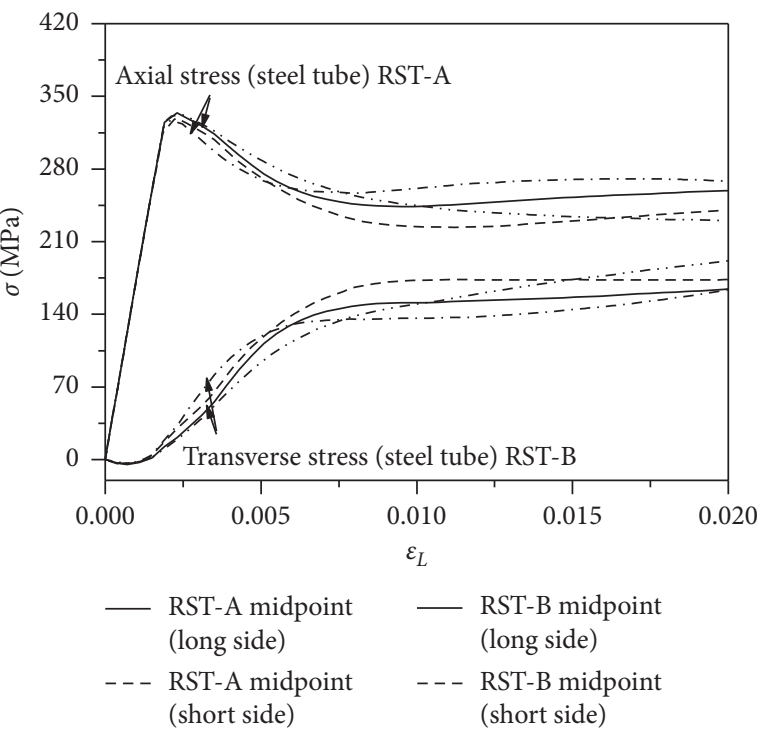

(c)

Figure 10: Comparison of the relationship between the stress and longitudinal strain of specimens. (a) Stress-strain relationship of the elliptical stirrup in the middle section. (b) Comparison of stresses at the endpoints of the concrete and steel tubes. (c) Comparison of stresses at the midpoints of steel tubes.

(2) In comparison with the core concrete longitudinal stress of the conventional rectangular CFT stub columns that of the confined ones increased due to the constraint action of the stirrups on the core concrete. When the tube stress reached the yield point, the longitudinal stress rates decreased, and the hoop stress increase accelerated. Hence, the confinement action of the steel pipe to the core concrete increased.

\section{Conclusion}

This study evaluated the static performance of rectangular CFT stub columns through testing and FE analysis. The following conclusions were obtained:
(1) Two conventional rectangular CFT, two SCFT, and two CCFT stub columns were included in the experiments. Test results showed that the stirrup confinement rectangular CFT specimens in axial compression could availably retard the local bucking of the steel tube and improve the ductility and ultimate bearing strength. In addition, the restraint effect of the elliptical stirrup was better than that of the stiffening ribs.

(2) The FE software Abaqus was applied to conduct a 3D solid FE model analysis on the axial compression of the rectangular CFT specimens. The calculation results fit well with the test results. 


\section{Data Availability}

The data in this paper include experimental result data and calculation result data. All the data used to support the findings of this study are included within the article. There are not any restrictions on data access.

\section{Conflicts of Interest}

The authors declare that they have no conflicts of interest.

\section{Acknowledgments}

This research work was financially supported by the Hunan Education Department Foundation Funded Project Grant nos. 18B438 and 14C0217, the China Postdoctoral Science Foundation Funded Project Grant no. 2018M632990, the Natural Science Foundation of Hunan Province, China, Grant nos. 2018JJ3021 and 2019JJ20029, and the National Key Research Program of China, Grant no. 2017 YFC0703404.

\section{References}

[1] Z.-B. Wang, Z. Tao, L.-H. Han, B. Uy, D. Lam, and W.-H. Kang, "Strength, stiffness and ductility of concretefilled steel columns under axial compression," Engineering Structures, vol. 135, no. 3, pp. 209-221, 2017.

[2] F. Yuan, H. Huang, and M. Chen, "Effect of stiffeners on the eccentric compression behaviour of square concrete-filled steel tubular columns," Thin-Walled Structures, vol. 135, no. 2, pp. 196-209, 2019.

[3] L. Guo, Y. Liu, F. Fu, and H. Huang, "Behavior of axially loaded circular stainless steel tube confined concrete stub columns," Thin-Walled Structures, vol. 139, no. 6, pp. 66-76, 2019.

[4] C. Petrus C, H. A. Hamid, A. Ibrahim, and G. Parke, "Experimental behavior of concrete filled thin walled steel tubes with tab stiffeners," Journal of Constructional Steel Research, vol. 66, no. 7, pp. 915-922, 2010.

[5] Z. Tao, B. Uy, L.-H. Han, and Z.-B. Wang, "Analysis and design of concrete-filled stiffened thin-walled steel tubular columns under axial compression," Thin-Walled Structures, vol. 47, no. 12, pp. 1544-1556, 2009.

[6] L. Jiang, Y. Liu, A. Fam, and K. Wang, "Fatigue behaviour of non-integral Y-joint of concrete-filled rectangular hollow section continuous chord stiffened with perfobond ribs," Engineering Structures, vol. 191, no. 7, pp. 611-624, 2019.

[7] Z.-B. Wang, Z. Tao, and Q. Yu, "Axial compressive behaviour of concrete-filled double-tube stub columns with stiffeners," Thin-Walled Structures, vol. 120, no. 11, pp. 91-104, 2017.

[8] F.-X. Ding, L. Fu, X.-M. Liu, and J. Liu, "Mechanical performances of track-shaped rebar stiffened concrete-filled steel tubular (SCFRT) stub columns under axial compression," Thin-Walled Structures, vol. 99, no. 2, pp. 168-181, 2016.

[9] Y.-L. Long and L. Zeng, "A refined model for local buckling of rectangular CFST columns with binding bars," Thin-Walled Structures, vol. 132, no. 11, pp. 431-441, 2018.

[10] Y.-T. Wang, J. Cai, and Y.-L. Long, "Hysteretic behavior of square CFT columns with binding bars," Journal of Constructional Steel Research, vol. 131, no. 10, pp. 162-175, 2018.

[11] Z.-L. Zuo, J. Cai, Q.-J. Chen, X.-P. Liu, C. Yang, and T.-W. Mo, "Performance of T-shaped CFST stub columns with binding bars under axial compression," Thin-Walled Structures, vol. 129, no. 8, pp. 193-196, 2018.

[12] Y. Chen, J. Feng, and S. Yin, "Compressive behavior of reinforced concrete columns confined by multi-spiral hoops," Computers \& Concrete, vol. 9, no. 5, pp. 341-355, 2012.

[13] L.-Z. Sun, D.-Y. Wu, J.-L. Zhao, F. Yang, and W. Li, "Behavior of circular RC columns with two layers of spirals," KSCE Journal of Civil Engineering, vol. 21, no. 3, pp. 955-963, 2017.

[14] GB 50017-2017, Standard for Design of Steel Structure, China Architecture and Building Press, Beijing, China, 2017, in Chinese.

[15] Hibbitt, Karlson, Sorenson Inc, Abaqus Version 6.8: Theory Manual, Users' Manual, Verification Manual and Example Problems Manual, Hibbitt, Karlson, Sorenson Inc., New York, NY, USA, 2012.

[16] F. Ding, X. Ying, L. Zhou, and Z. Yu, "Unified calculation method and its application in determining the uniaxial mechanical properties of concrete," Frontiers of Architecture and Civil Engineering in China, vol. 5, no. 3, pp. 381-393, 2011.

[17] J. Liu, F.-X. Ding, X.-M. Liu, Z.-W. Yu, Z. Tan, and J.-W. Huang, "Flexural capacity of steel-concrete composite beams under hogging moment," Advances in Civil Engineering, vol. 2019, no. 3453274, pp. 1-13, 2019. 


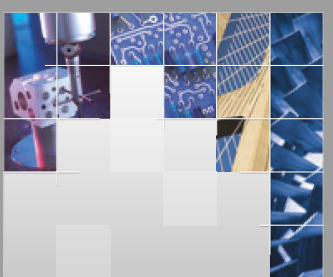

\section{Enfincering}


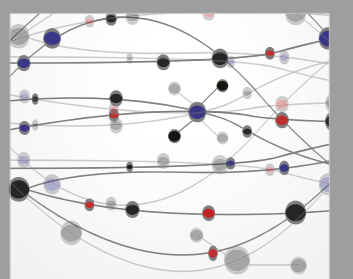

\section{Rotating \\ Machinery}

The Scientific World Journal

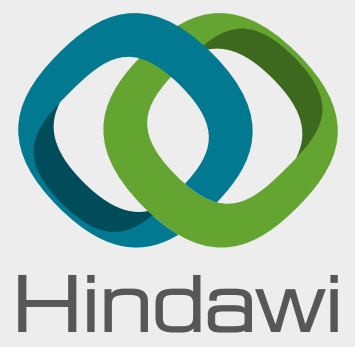

Submit your manuscripts at

www.hindawi.com
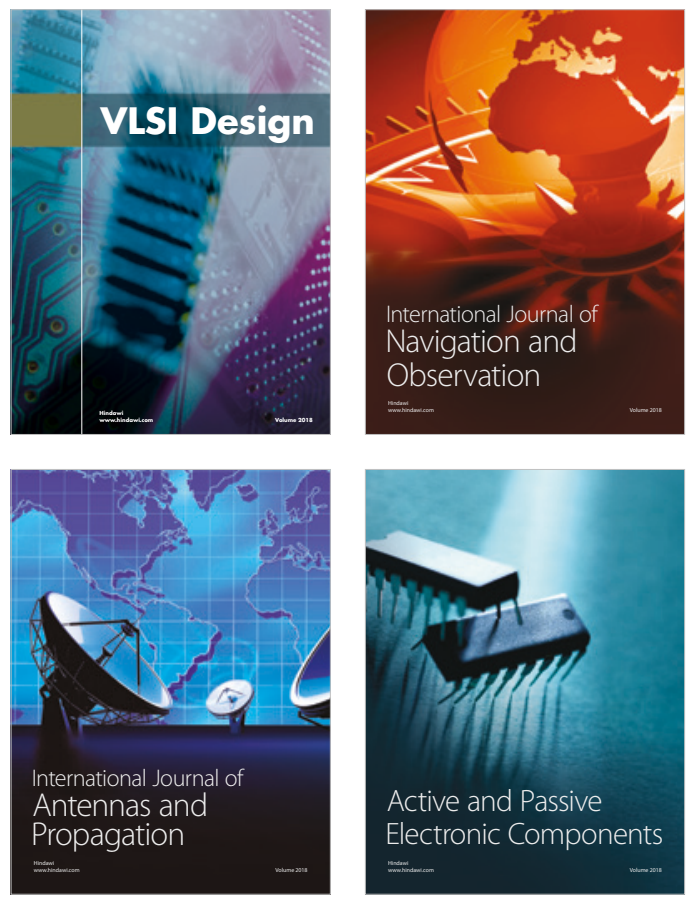
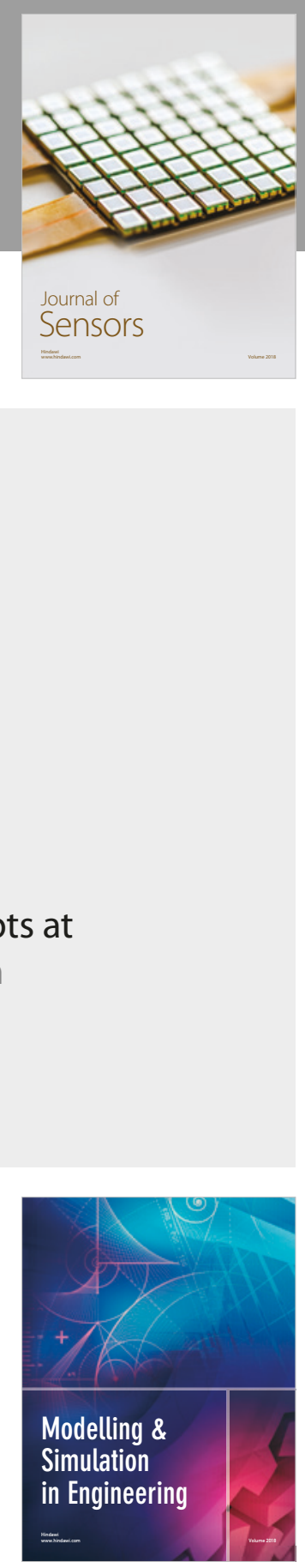

\section{Advances \\ Multimedia}
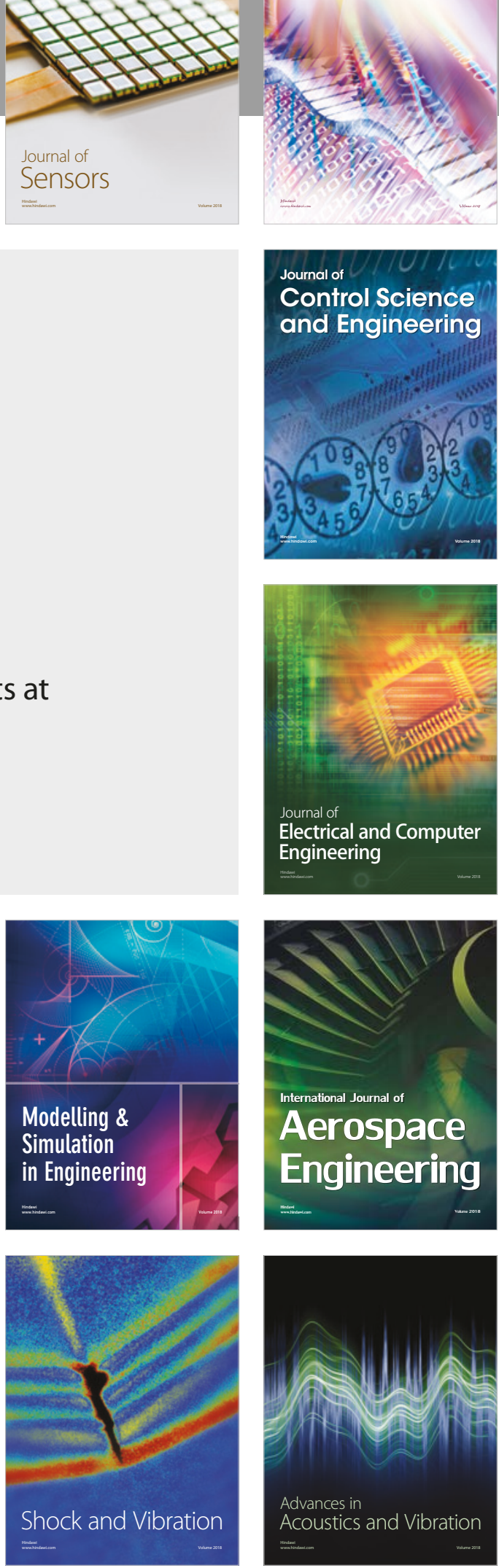